\title{
Early Regulations of Distributed Ledger Technology/Blockchain Providers: A Comparative Case Study
}

\author{
Hans Jochen Scholl \& Roman Pomeshchikov \\ University of Washington, WA, USA \\ $<$ jscholl,romanpom>@uw.edu
}

\author{
Manuel Pedro Bolívar Rodríguez \\ University of Granada, Spain \\ manuelp@ugr.es
}

\begin{abstract}
Distributed Ledger Technologies (DLTs) such as Blockchain have been heralded for their potential to fundamentally disrupt traditional industries and longstanding practices in private and public businesses. In the financial sectors, for example, quite a number of novel financial technology (FinTech) services based on DLT/Blockchain have been introduced with cryptocurrencies representing prominent cases. While the already highly regulated financial sectors have emerged as early targets for DLT/Blockchain induced disruption, a diverse set of other areas, such as healthcare record keeping, insurance record keeping, industrial and retail supply chain management, property registries, citizen identification systems, and voting systems to name a few, has also come into the focus of DLT/Blockchain innovation. These new types of services might be in need of both complementary and novel regulations for DLT/Blockchainbased services. Interestingly, smaller jurisdictions such as Gibraltar, Malta, and Liechtenstein were among the first to provide advice and regulation for DLT/Blockchain service provisions. The study compares these early regulatory approaches to each other and discusses the prospects of DLT/Blockchain service regulation based on the study's findings. DLT/Blockchain service regulation appears to incorporate predominantly principle-based rather than rule-based regulations, which makes the regulation enforcement a uniquely individual case-based task.
\end{abstract}

\section{Introduction}

Initially, when Distributed Ledger Technology (DLT) debuted in the first decade of the $21^{\text {st }}$ century its overall disruptive potential remained widely uncovered. Only with the advent and success of cryptocurrencies, which are based on Blockchain, a DLT implementation, the unique and broad capabilities of the technology became more widely understood [28]. Post-hoc non-falsifiability or immutability of transactional records, security of transactions in an append-only ledger-type environment, transparency of transactions, and reduction of transaction costs as a result of the former three characteristics were among the distinguishing capabilities of
DLT/Blockchain [14, 22, 25, 28, 31]. Moreover, via smart contracts based on predefined algorithms DLT-based transactions could be automatically executed in case the contractual conditions were satisfied, which would further drive down transaction costs and speed up the transactional process. In the financial sector, the implications of cryptocurrencies and also smart contracting were quickly understood also with regard to their quality to eliminate the need for services from central counterparties such as banks [14].

Forced by the success of unregulated cryptocurrencies and other DLT-based financial technology (FinTech) services, which had grown to a sizable global economic entity by the mid of the second decade of the $21^{\text {st }}$ century, lawmakers and regulators around the world began to investigate the options for regulating the novel phenomena for reasons of gaining control over DLT-based money flows (in terms of anti-money laundering and anti-terrorist financing interests) as well as for establishing baseline security and protection for investors and investments [3, 7 , 19, 21, 24, 34].

While large jurisdictions such as the Federal Government of the United States (US) and the European Union (EU) as well as other nation states have either taken a caseby-case approach like the US, or have been intentionally slow in deliberating, crafting, and agreeing on explicit overall DLT service-related regulations, a few smaller jurisdictions such as Gibraltar, a self-governed overseas territory of the United Kingdom (UK), the EU member state of Malta, and more recently the EU associate Principality of Liechtenstein have moved more quickly towards formal hearings on proposed DLT service-related legislation and regulation. Finally, in quick succession respective regulations went into effect in 2018 in Gibraltar and Malta. We would have liked to include the also self-governed British island of Bermuda in this study. While we collected comprehensive documentation on Bermuda's regulation of DLT-related service provisions, we were unable to persuade any of Bermuda's stakeholders to be part of this study as interviewees, which prevented arriving at a multistakeholder perspective on the nature of the regulation, its motivations and expectations along with other clarifications and interpretations of the regulatory effort in the case 
of Bermuda. Therefore, we finally refrained from including the case in this project.

This study explores the nature of the respective regulations, their objectives and expectations as seen by regulators, as well as their effects on DLT service providers. In comparing the early regulation attempts and their already observable effects the study aims at better understanding the regulatory choices and challenges as well as the potentially enabling and constraining outcomes of various regulatory approaches on DLT-based services.

The paper is organized as follows: First, the academic literature on DLT/Blockchain provider regulation is reviewed followed by a presentation of the resulting research questions and the methodology section. Subsequently, the study findings are detailed leading to the discussion of insights from the findings. At last, conclusions are drawn, and the directions for future research on the subject are sketched out.

\section{Literature Review}

The academic literature on the regulation of DLT/Blockchain providers and service provision is still relatively small. While the term "regulation" itself has received different interpretations [21], in which some authors relate to a fixed set of hard rules, the compliance to which requires adequate enforcement, others see in regulation the willful causation of desirable behavior within certain boundaries. Some debate has ensued regarding the appropriateness of legal and/or regulatory provisions for technology itself rather than for the framing of productive uses of technology and for preventing harmful ones. Digital technology, it has been argued, develops too fast and changes too quickly such that any regulatory efforts targeted at the technology itself and its specificities might be outright ineffective, be outdated quickly, or even have undesirable and stifling side effects on the technological progress [21]. In that context, Moses quotes Eastbrook's 1996 argument, in which the judge refers exempli gratia to an imaginary "Law of the Horse," which would be impossible to effectively formulate for sake of its endlessly enumerable instantiations [21]. Furthermore, as Moses also holds, regulators face the twin hurdles, one of which is the so-called Collingridge dilemma according to which in the early stage of digital technology evolution, any regulation would be highly speculative in the absence of unknowable outcomes with or without regulation, while at a later stage with more mature new-technology uses the regulation might become overly disruptive to the evolved statusquo [6]. The other hurdle is given by the "uncertainty paradox" according to which the assessment of risks regarding regulatory outcomes as opposed to those outcomes under no regulation would be equally unknowable at the time of regulation [15].
In the rapidly evolving FinTech sector, novel uses based on DLT/Blockchain technology, for example, the creation of crypto-currencies and their trading on DLTbased exchange platforms, have so far greatly outpaced undertakings to provide legal or regulatory frameworks [23]. Lastra \& Allen point at the three border problems that any regulation of cyber services has to address: (a) the need for distinguishing the regulated from the unregulated activities and the so-called contagion problem in case of crossovers between the two realms, (b) the need for identifying the realm and reach of a regulation, which is enacted by a jurisdiction on national or sub-national levels, and (c) the need for identifying the realm and reach of a regulation, which pertains to services provided in cyberspace and the "real world" [20]. Three distinct areas of potential regulation have been identified, (a) virtual or crypto currencies, (b) initial coin offerings (ICOs) and crypto tokens, and (c) smart contracts [5].

Crypto-currencies such as Bitcoin and Ether have received differential legal treatments from jurisdictions around the world, which range from strict prohibition over legally considering them assets or commodities representing some exchange value all the way to regarding them as quasi-money, however, without legal tender status $[5,12,16,17]$. In the latter cases, globally well-established frameworks such as anti-money laundering (AML) and combating financing terrorists (CFT) would apply also to these DLT/Blockchain-based services $[12,16]$.

ICOs and crypto tokens have also been legally treated by jurisdictions in a similarly large range of ways from entire banning (China, South Korea) to considering them securities or commodities under existing laws on a case by case basis (US, Switzerland) to some regulation (Gibraltar, Canada), to not regulating them at all $[5,20]$.

Beyond the quasi-monetary or security-type instantiations of crypto-currencies, academic accounts of regulatory needs have pointed at DLT service areas such as media of exchange, payment rails [20], and notarial, that is, non-monetary uses [14] such as document verification, authorship authentication, and contract enforcement [19] as well as title registries, licensing services, authentication/identity services, health insurance record keeping [1, $4,17]$, asset registries, application stacks, or other assetcentric technologies [23] among others [14]. As Siegel outlines, digital tokens have four distinct characteristics: They may be either (a) fungible and transferable (for example, like coupons or tickets, or (b) fungible and nontransferable like club memberships or application accounts, or (3) unique and transferable such as lottery tickets or car titles, or (4) unique and non-transferable such as driver's licenses or drug prescriptions [29]. Regulation of tokens and token-related services, hence, needs to account for these characteristics and use cases. 
Smart contracts, tightly related to crypto-currencies, ICOs/tokens, represent another new realm and target of potential DLT-related service regulation. Smart contracts typically embed algorithms in digital tokens, which under predefined conditions automatically execute legally binding transactions such as payments or transfer of ownership of digital assets. Regulatory efforts and assessments need to clarify to what extent common law covers such algorithmic agreements, or in turn, comply with existing laws, or assume a legal standing on their own [5]

Overall, regulation and licensure along all these lines are seen as enablers for DLT/Blockchain provision by decreasing legal risks for licensed providers and safety, fraud, and mishandling risks on part of service recipients [19].

However, as Zetsche et al [36] emphasize, whatever regulated DLT-based service is provided, legal liabilities (and associated risk-related costs) will not vanish. Rather four dimensions of legal liability have to be considered in regulated DLT-based service provision, since these might be sources of risk proliferation: (1) liability as a result of breach of contract (for example, in a permissioned ledger between the partners), (2) liability resulting from a partner's control rights (again in permissioned ledgers), (3) case-specific liability even in unpermissioned ledgers, and (4) legal entanglement from joint liability when operating across jurisdictions with different liability statutes.

Furthermore, as Ramsay observes, DLT/Blockchain principles of operation and their regulation might create a Gordian legal knot when it comes to tension and outright conflict between (regulated) DLT/Blockchain service provision and other regulations such as the EU's latest General Data Protection Regulation (GDPR) of 2018 [24], the latter of which grants to individuals and institutions the per-request right to erasure, rectification, and restriction of processing of personal data, which would be a technically unfeasible task to perform on any permissionless distributed ledger and still a daunting one on permissioned distributed ledgers depending on the number of nodes.

In summary, most of the legal and regulatory territory around DLT/Blockchain service provision, in general, and around crypto-currencies, ICOs/tokens, and smart contracts, in particular, is uncharted, and, maybe even unchartable under a traditional regulatory approach. It also appears that in the absence of some level of regulatory harmonization on a global scale, DLT/Blockchain service provision might remain a riskheavy undertaking. Insofar, regulatory initiatives such as the ones investigated in this comparative study might help pave the path to the better understanding of challenges and opportunities of regulation in this area and its potential for legal harmonization.

\section{Research Questions}

This then leads to the following research questions:

\section{Research Question \#1 (RQ\#1):}

How do the investigated regulatory approaches compare?

\section{Research Question \#2 (RQ\#2):}

What are motivations and challenges for regulating DLT providers/provision at an early stage?

\section{Research Question \#3 (RQ\#3):}

How are the identified challenges addressed in the various approaches of early regulations?

\section{Method Section}

Approach. Comparative case studies have been a preferred method of investigation, when the phenomena under study were theoretically not yet well understood and the expected accumulation of knowledge rested on particular contexts [11] within real-life social settings [35]. By searching for motives, reasons, potential causes as well as for ways, means, and manners of actors' relationships and actions within the phenomena under investigation the resulting rich descriptive accounts in comparative case studies reach for theory development or theory revision $[9,11,35]$.

Instrument and Coding Scheme. The literature on regulatory benefits and challenges in the DLT/Blockchain realm informed the development of a semi-structured interview protocol in four topical areas of (1) general information, (2) perceptions of and motivations for DLT provider/provision regulation, (3) state of legislative and regulatory process, and (4) challenges and outlook within the broader context of DLT provider/provision regulation. The instrument incorporated a total of fifteen interview questions along with thirty anticipatory subquestions for further probing.

Sample. After the British overseas territory Gibraltar had incorporated a worldwide first DLT provider/provision regulation in early 2018 , which was studied separately, the jurisdictions of Malta and Liechtenstein were the next to follow with DLT/Blockchain regulations. In a purposive sampling approach [26], a total of twenty individuals from the three jurisdictions (Gibraltar, Liechtenstein, and Malta) representing primary stakeholders such as regulators, government officials, legal advisors, lobbyists, FinTech firms, developers, and licensees, were identified and interviewed in person.

Data Collection. The two main sources of data collection were the regulatory documents and the in-person interviews. Interviews were conducted either in person or via an industry-grade and encrypted videoconferencing 
tool (Zoom, version 4.1.34801.1116) between late fall of 2018 and spring of 2019. The interviews lasted between 41 and 99 minutes with an average of 62 minutes and a median of 69 minutes. The interviews were recorded, transcribed, and coded for analysis. Furthermore, interviewers took notes during the interviews. Besides the legal documents other documents such as press interviews were collected, reviewed, and coded as appropriate.

Data Analysis and Coding. The codebook followed the questionnaire regarding the breakdown of (1) main questions and sub-questions (2) perceptions of and motivations for DLT provider/provision regulation, (3) state of legislative and regulatory process, and (4) challenges and outlook within the broader context of DLT provider/provision regulation producing initially 15 category codes and 30 sub-category codes. Additional codes were inductively introduced during data collection, in individual coding sessions, and inter-coder sessions $[27,30,32]$. Since a codebook in a hybrid approach of deductive and inductive analyses [10] is designed to be open to extension, it ultimately encompassed 57 sub-category codes in the four main categories. Whenever evidence from the data supported it, relationship links between concepts were established, which were not interpreted as causal links.

\section{Findings}

5.1 Ad research question \#1 (How do the investigated regulatory approaches compare?):

Gibraltar, while still a part of the European Union (EU) before the United Kingdom's leaving the EU (Brexit), was the first jurisdiction to regulate the provision of DLT-based services. The respective law went into force on January 1, 2018 as Financial Services (Distributed Ledger Technology Providers) Regulations 2017, legal notice No. 204. The legislation amended previous financial-sector regulations such as the Principal Act as well as the Financial Services (Licensing) Regulations of 1991, the Financial Services (Penalty Fees) Regulations of 1993, and Financial Services (Fees) Regulations of 2016. The DLT Provider Regulation of 2017 defined DLT-based services as a "way of business" that uses "distributed ledger technology for storing and transmitting value belongings to others" (p. 2481). It further defines DLT as "a database system in which (a) information is recorded and consensually shared and synchronized across a network of multiple nodes; and (b) all copies of the database are regarded as equally authentic" (p. 2481). Additionally, "value" is defined as to include "assets, holdings and other forms of ownership, rights or interests, with or without related information, such as agreements or transactions for the transfer of value or its payment, clearing or settlement" (p. 2481).
The Gibraltar regulation, hence, provides a vast umbrella definition of value stored and transferred via DLT, which can contain anything from securities over commodities to ownership rights of physical objects such as pieces of art, which would normally not fall under the jurisdiction of the Gibraltar Financial Services Commission (GFSC). The Gibraltar DLT Provider Regulation is unique in that it refrained from addressing information technology in any specific terms other than the most general and neutral. It is also unique in its desistance from specifying any hard rules, with which DLT licensees have to comply. It rather lists nine principles, which include (1) honesty and integrity of business conduct, (2) due regard to customer needs and fair communications, (3) adequacy of resources, (4) effective management and control, also with regard to risk, (5) effective protective arrangements, (6) effective governance arrangements, (7) system security, (8) systems of detection and prevention of crime, and (9) provisions for orderly wind down of business.

While the regulation leaves room for non-financial uses of DLT service provision, its regulatory home was seen under the roof of the GFSC, which vets DLT provider applications and grants DLT provider licenses. The GSFC has sweeping powers in licensing, monitoring, and enforcing compliance with DLT-based and traditional financial services. GFSC also enjoys flexibility and a wide range of interpretative space for assessing and evaluating the soundness and viability of the business of any given DLT provider licensee. Throughout the first year of the regulation in force (2018) a total of four licenses were granted, the businesses of three of which were in operation in the crypto exchange market arena, and another dozen licenses were close to being granted in the first half of 2019 .

Interestingly, despite, or, rather because of the wide definition of DLT-based service provision, Gibraltar legislators felt compelled to formulate a proposal for a "Token Regulation," which compensates for the existing lack of token-specific regulation (see Gibraltar Finance, http://gibraltarfinance.gi/20180309-token-regulation--policy-document-v2.1-final.pdf, accessed September 21, 2018). The respective regulation was expected to pass the Gibraltar Parliament in the fall of 2018; however, it has since been stuck in the process.

Liechtenstein, a European Area (EA), that is, EU-associated country, had entered (by early June 2019-the time of this writing) the stages of parliamentary proceedings for a comprehensive and detailed regulation of services forming a "token economy" built upon so-called "trustworthy technologies" [13]. The interviewees expected that the respective comprehensive regulation would be passed and in force by January of 2020. While other jurisdictions more narrowly focus their regulations and proposals for regulation on the area of financial 
services and also in some cases touch on technologyspecific aspects of the phenomenon, the Liechtenstein regulation is deliberately broad and technology neutral. While it considers unique characteristics of Blockchain technology as examples, the proposed legislation refers to digital services based on "trustworthy technologies," which extend far beyond financial assets such as currencies and securities into values including utility coins, commodities, raw materials, real estate, other physical objects (in general), patents, copyrights, machinery, and entitlements, among others. In the Liechtenstein regulatory perspective, the tokenization of these items of value and ownership provides for the evolution of the socalled "token economy." For this to materialize, the creation of tokens, which are seen as initially empty "containers," in and through which whatever tangible or intangible value can be represented, has to be regulated along with the safe storage and maintenance of such tokens. Furthermore, the regulation has to encompass secure trading and exchange of tokens including public token offerings, general related services, and private investments.

The broad scope of Liechtenstein's regulation creates numerous points of connection and intersections with other laws and regulations, which as a consequence are in need of amendments such as the Due Diligence Act (anti-money laundering/AML and combating-financing terrorists/CFT) and the Financial Market Supervision Act, which basically gives the Financial Market Authority (FMA) strong oversight over the regulated token economy as defined by the TVTG (TTTA, that is, Token and Trusted Technologies Service Provider Law). Furthermore, amendments had to be made to existing Civil and Corporate Law to include TVTG-related "value rights" as well as to the Commercial Law with regard to TTTA providers. Once in force, the Liechtenstein regulation of DLT/Blockchain/Tokens would be the most comprehensive of its kind so far.

Malta, a EU member state, has a history of successfully attracting business opportunities like Gibraltar, which for the lack of conducive and accommodating legislation have difficulties to develop their full potential elsewhere. Both Malta and Gibraltar competed in developing such legal environments for the unfolding online gaming businesses as early as the late 1980s. In both cases, major global players in that particular business segment were attracted to making their operations home in these regulated environments leading to major increases of wealth and tax revenue as well as high-technology know-how influx in the two jurisdictions. With the appearance of cryptocurrencies, businesses and lawmakers in both jurisdictions understood early that a similar opportunity was likely at hand. The approach, which Malta has taken, however, is different from the two aforementioned ones. With much fanfare ("Malta, the
Blockchain Island") three pieces of legislation went into force in November of 2018. The first, the Virtual Financial Assets Act (VFAA) regulates "the field of Initial Virtual Financial Assets Offerings and Virtual Financial Assets" and related services and matters. It defines a DLT asset as a virtual token, a virtual financial asset, electronic money, or a financial instrument (VFAA, cap. 590, p. 3). In nine major sections and a total of 62 paragraphs VFFA provides detailed regulations regarding requirements for licensing, application procedures, administration and obligation of license holders, prevention of abuses, regulatory and investigatory powers, auditing, appeals, sanctions etc., among others. The VFA Act also introduces the institution of a registered "VFA agent" (VFAA, cap. 590, p. 6), typically a lawyer, accountant, or auditor (firm) through whom and which VFA offerings can be licensed. The VFA Act is accompanied by the Malta Digital Innovation Authority Act (MDIAA), cap 590, and Innovative Technology Arrangements and Services Act (ITAS), cap 592. While the former act introduces a new supervisory and advisory authority, the Malta Digital Innovation Authority (MDIA), geared at guiding and supervising the implementation and uses of novel technologies, the latter is designed for regulating such novel technologies as need emerges. DLT Service-related licenses have to clear several hurdles in Malta before they are granted. The technology arrangements need to certified by MDIA under ITAS, whereas the financial business-related arrangements undergo a review and approval by certified VFA agents, the license of operation for which is then ultimately granted by the Malta Financial Services Authority. As it appears, the technology certification and the (financial) business certification involve and follow two separate, but ideally parallel, processes. The MDIA Act states that an "array of other national competent authorities" might have a say in the certification processes. It will remain to be seen how effective and time-efficient the two-pronged certification process works.

In summary, the three regulatory approaches employ fairly distinct regimes and processes. While Gibraltar was the first to provide a regulatory framework, it purposefully remained vague and unspecific about technology and token-related matters, whereas Malta not only implemented a new technology-focused agency, but also involved another intermediary, the VFA agent, into a twopronged certification procedure. Liechtenstein, on the other hand, envisioned and tried to foster the emergence of a whole-new token economy with a comprehensive, however, clear approach that appears to be well integrated into existing legal frameworks beyond the financial frameworks.

5.2 Ad research question \#2 (What are motivations and challenges for regulating DLT providers/provision at an early stage?): 
As will be shown in the following, the motivations for regulating DLT/Blockchain/Token service providers as well as the perceived challenges of such regulations were seen in similar, if not the same ways across the three jurisdictions, which is why they are presented below forgoing the breakdown used in the previous section to avoid unnecessary repetition.

In 2017, the year before the regulation in Gibraltar and Malta went into force, about $\$ 6.6 \mathrm{~b}$ had been raised in the eleven largest cryptoasset offerings alone in a global ICO marketplace without much of a legal protection or regulation [18]. Without exception the value of these crypto holdings had all fallen significantly until the end of that same year, in some cases by up to 98 percent. Besides the inherent riskiness and volatility of these particular kinds of investments, however, over 80 percent of cryptoasset projects in terms of number of shares were identified as scams [8]. It was feared by both FinTech stakeholders and regulators in the three jurisdictions (Gibraltar, Liechtenstein, and Malta) that the very high burn rate observed in ICOs and purposefully abusive uses in permissionless environments could effectively suffocate a novel and highly attractive business opportunity before it had even fully developed. Regulation, hence, was considered an urgent necessity to prevent that from happening. An equally strong motivation on part of major stakeholders in the three jurisdictions in favor of DLT/Blockchain/Token regulation was the desire to move fast and decisively for seizing what was considered a unique and rapidly emerging business opportunity before larger jurisdictions would be able to put their own respective stakes in the ground. Bolstered and enabled by their relatively small sizes, manageable number of stakeholders, and arm-length decision-making processes the three jurisdictions enjoy high degrees of agility and flexibility that make such early and fast legislative moves possible. This, in turn, was expected to attract serious and reputable businesses in the evolving FinTech sector and adjacent service areas by establishing legal certainty along with secure and safe operational settings for cryptoasset exchanges and other DLTbased service provisions. Explains a Gibraltar government official,

"If there is no framework, and there is no control, and there is no transparency, it is going to crash and burn. So, we have taken the view, let us allow it, but control it, regulate it, and ensure that everybody is involved in it and knows what they are doing... By regulating we brought the good ones in and kept the bad ones out. They have got to go through the Financial Services Commission, pay fees, invest in the place by putting people here and by putting offices here. And that is going to push away the bulk of people that we do not want here." (quote \#01)

However, other motivations also included the prospect of and potential for reforming the financial and other service arenas via groundbreaking innovations with the hope of making markets more equitably accessible. As a Liechtenstein regulator holds,

"One of the big visions...is to democratize financial services again. Now you have the financial services in the hands of a few powerful players. And in the future, every small- or medium-sized company can issue shares without going to the bank..., and that will help innovation." (quote \#02)

In all three jurisdictions, another strong common motivation for effective regulatory action was the protection of their international reputation and "good standing" as a financial service hub and an internationally credible guardian against AML and CFT. Said a Malta legal advisor to the government,

"At the moment, this country unfortunately is subject to a lot of negative press relating to some abuse in relation to money laundering and financing services. So, if you want to start fixing the situation, you see that this technology can help solve that problem, then the faster you move, the better the opportunity is." (quote \#03)

Finally, interviewees from all three jurisdictions acknowledged that in the future and in order to remain compliant, adjustments to the local regulations might become necessary as soon as major jurisdictions such as the EU or the US establish their own legal DLT/Blockchain/Token frameworks. In this regard, some interviewees saw the EU and some of their member states moving faster than the federal government of the United States and some federal states within the union. Liechtenstein interviewees, particularly, expressed some confidence about their approach to potentially become the role model for neighboring countries like Switzerland and Austria, but potentially for the European Area as a whole.

In summary, while the regulatory approaches as shown above vary to quite some extent, the motivations of and the perceived challenges for regulating DLT/Blockchain/Token service providers were seen in very similar ways across the three jurisdictions. The ability to move fast due to small size and agility helped facilitate regulatory action geared at (1) preventing the abuse and consequential annihilation of a potentially grand economic opportunity, (2) attracting and retaining serious and solid players to a regulated and safe business environment, thus, capturing economic opportunity, (3) protecting the respective jurisdiction's reputation, and (4) fostering fundamental innovations by creating a "token 
economy" with democratized access, and (5) serving as a poster child for regulatory approaches of others.

5.3 Ad research question \#3 (How are the identified challenges addressed in the various approaches of early regulations?):

Gibraltar had received a little under forty license applications until the end of 2018, five of which had been meticulously vetted and granted (Coinfloor, Covesting, GBX-Gibraltar Blockchain Exchange, Huobi, and eToroX) by the Gibraltar Financial Services Commission (GFSC), and the first three of those listed had started regulated operations in the territory before the end of that year. These licensees appear to meet the criteria of business prowess and reliability. Since commencing operations the five licensees mainly have focused on providing exchange platforms for the trading of cryptocurrencies. With the more specific token regulation still pending, it is currently unclear how the firstmover advantage will be fully captured and maintained. By the end of 2018, with a staff of under one hundred the GFSC had had dedicated a single digit number of staffers to reviewing applications and to monitoring licensed DLT provider businesses. Since licensed DLT provider services are expected to become increasingly diverse and require highly sophisticated subject-matter expertise for effective oversight on part of the regulator, the hiring of new expert staff appears a midterm necessity. However, using the example of the gaming industry, the Gibraltar interviewees were in agreement and fairly adamant that they were neither expecting and nor inviting hundreds of applications but ultimately rather more like dozens of solid DLT provider businesses operating from the territory. The current license holders appeared to match these criteria also with regard to upholding Gibraltar's good reputation. As one legal advisor maintains,

"Reputation is always key in these areas because we want to be here for a long time. Not just shortterm venture where you make a lot of money and then disappear. That I think has been the aim of the regulator and the government as well. Certainly, we will feel comfortable with that too as lawyers, knowing that everybody is thinking alike, and we are looking for a similar kind of clientele that fit certain criteria." (quote \#04).

It remains to be seen though to what extent Gibraltar's regulatory approach can serve as a role model for other jurisdictions, although elements such as the "nine principles" seem to resound in other legislative approaches (for example, Malta's VFAA, cap 590, p. 12) at least in part.

Liechtenstein, unlike the other two jurisdictions covered by this study, did not have DLT/Blockchain/Token legislation in force at the time. However, the proposed legislation appears to be well-integrated with existing law, and in particular, with financial service-related legislation. In anticipation of the pending regulation and licensed on grounds of existing financial law, Binance, a major player in the global cryptocurrency arena, has launched a fiat-to-crypto exchange as a joint venture with Liechtenstein Cryptoassets Exchange (LCX). By the spring of 2019, The FMA had received over 250 license applications, a few of which launched operations in a sandbox-similar fashion under the auspices of the FMA. However, the high number of application also seems to indicate strong interest in the innovative potential of the broader token economy as envisioned and facilitated by the upcoming legislation and the guidance by the FMA. As a Government Official points out,

"If you only look at the financial market regulation applications, there was really no need to actively change something because if you tokenize a security, the security laws apply in Liechtenstein. Also, the financial market law applies to that section. There is just the question about bitcoins and utility coins that is open at the moment. But we have seen there is a lot more potential in the rest of the token economy. And if you want to tokenize a physical asset, if you want to tokenize a car, a supply chain, and all the possible applications of the token in the industry besides the financial market. And that was the reason why we find a broader approach to regulate." (quote \#05)

Once the legislation goes into force, it will be seen how effective it is, how well the supervision by the FMA works, and how it facilitates service innovation across a large range of areas far beyond the financial sector. While it appears wise to initially charter the FMA with the licensing task and the oversight, other supervisory entities might need to become involved as the token economy unfolds. The Liechtenstein legislation shows some teeth also with regard to specifying criminal infractions of the regulation and respective punishments.

Malta, for reasons of too permissive handling of DLT services already operating from its territory before the regulation, and in particular, for lax enforcement of AML and CFT measures, had come under serious pressure from both the United States and the European Commission [33]. As seen, the jurisdiction responded with establishing fairly detailed and comprehensive legislation, which tried to strike a balance between stricter oversight and maintenance of the innovative space it intended to provide. Licensees have to go through two licensing authorities, which cover the technology and the business side of the application. The technology side is covered by MDIA, a brand-new authority. For the business side, certified agents had to be involved, which act as the subject matter 
experts on behalf of the MFSA. By spring 2019, however, only about a dozen VFA agents had been certified, so that the applications from DLT/Blockchain/Token businesses already in operation in the country under a transitory regime since November 1, 2018 had still remained in an unlicensed or preliminary status. From that end, the recent admonishment by the EC demanding stricter oversight (see above) is coherent. In part, this problem is also reflected in a lobbyist's critical remark about the regulation,

\begin{abstract}
"Potentially, we over-regulated the whole thing, and the reasons there, even though I think the intention was good, are many. One, the Malta Financial Service Authority did not want to take any risks. You also need to factor in the international climate or international perception, which Malta managed to achieve in the past few years. We are mentioned in the Panama Papers, where we are seen as a tax haven etc. So, the MFSA had to build something new, and they set the bar too high. It is almost like having an initial public offering when it is not like that. So, that might have killed that industry per se." (quote \#06)
\end{abstract}

It appears that the current regulatory situation has not yet effectively prevented abuses in the DLT provider market, nor has it helped repair Malta's currently stricken reputation, although the ESMA Advice notice of January 2019 [2] explicitly refers to Malta's regulation as to basically heading into the right direction; however, at the same time the agency also points at the high failure rate in VFA agent certifications.

In summary, the challenges of abuse prevention, business development, reputation management, innovation, and role modeling in the rapidly evolving DLT/Blockchain/Token space are addressed in different ways by the three jurisdictions. In the case of Gibraltar, based on a regulation with some interpretive wiggle room, a highly selective licensing regime is applied. Liechtenstein's regulation appears to be the farthest reaching with the intent of creating an entirely new token economy, while Malta's detailed and two-stage regulation appears to be influenced as much by remedial efforts and damage control as by first-mover opportunity objectives. In that, the latter might lack in part the attractiveness of the other two regulation regimes from a business perspective.

\section{Discussion}

Risk, Opportunity, and Regulation. The US Securities and Exchange Commission (SEC) and the Commodity Futures Trading Commission (CFTC) along with European counterparts such as the three ESAs, that is, the European Securities and Markets Authority (ESMA), the European Banking Authority (EBA) and the European Insurance and Occupational Pensions Authority (EIOPA) have been vocal and clear in their repeated warnings against the risks incurred when investing in cryptocurrencies and digital assets. That notwithstanding the market capitalization of the leading 100 virtual currencies was estimated to have reached a volume of \$281.3b (https://coinmarketcap.com - accessed June 14, 2019). This volume cannot be explained just on grounds of dirty funds and dirty sources of funds in the AML and CFT sense. What this demonstrates, is that rather despite all warnings tremendous appetite for risk and for capturing what is seen as a unique opportunity exists. As argued elsewhere [28], regulating an unfolding technology-facilitated global economic innovation in a non-stifling fashion is by no means a trivial task, which, however, when done smartly can create tremendous public value along various lines. As seen in the findings to RQ\#1 the early regulations in the DLT/Blockchain/Token provider space by the three small jurisdictions may come from a standpoint of strong self-interest in the first place, but it is rather also reflective of the necessity to provide guidance as well as enforceable and safe pathways towards developing and entertaining novel business models and methods, which, in fact, helps create public value.

From that perspective, it would be helpful if large jurisdictions such as the US and the EU also followed suit and moved more quickly with developing respective regulatory frameworks. Issuing warnings is neither sufficient nor good enough for a dynamic environment and clearly articulated business need as this one.

Laws in Tension and Harmonization of Legislation. When regulating the DLT/Blockchain/Token provider space, existing laws might not only be in need of amendments, but they might rather also be in tension with any given DLT/Blockchain/Token provider regulation. As mentioned above [24], a case in point may be the EU's General Data Protection Regulation (GDPR), which introduces the principle of extraterritorial applicability, which increases the reach of this particular regulation globally. While one can argue that via built-in cryptography the data and privacy rights of individuals are effectively protected in a Blockchain for the most part, the technology itself powerfully and effectively defeats the GDPR "right to be forgotten," once the cryptographic shield has legally or illegally been removed. Furthermore, due to the inherently global nature of distributed technology ledgers, liabilities may be incurred under the laws of involved jurisdiction, which are unknown, or even unknowable, to both the regulated DLT service provider and the client. While it is illusory to hope that all such potential legal ambiguities and vagueries can ever be resolved in a global context, it also demonstrated that some extent of regulation harmonization might be conducive to providing firm legal foundations for operating safely in 
the DLT/Blockchain/Token provider space as the findings from RQ\#2 suggest.

Smart Contracts. As shown in part in the findings to RQ\#3, one of the most attractive, since dynamic, features of the token economy is the use of smart contracts. Elsewhere, the implications of "law becoming code" and "code becoming law" have been discussed [7]. When it comes to the regulation of DLT service providers, this particular aspect can be addressed in various ways (for example, in Gibraltar and Malta, the principle of fair and honest business conduct covers the issue in an umbrella type of fashion). However, once it comes to regulation enforcement and practical oversight, smart contracts, and in particular, intelligent smart contracts, which can change upon dynamically changing conditions, is not a trivial undertaking. Even if unlawful behavior in this context is finally detected, remedial action might no longer be possible. Vetting the algorithmic soundness by technically versed lawyers, which are currently hard to get by, might be a necessary requirement at the outset. However, smart contracts, which entail and use artificial intelligence (AI)-based algorithms might be hard to evaluate both ex-ante and ex-post. In other words, despite effective and widely harmonized regulations, some areas remain to be better understood in their ultimate consequences.

\section{Conclusion}

This study's object was to contribute to the deeper understanding of DLT/Blockchain/Token service provider regulation and its potential effects. However, our interest was not derived from a national or international law perspective. We were rather interested in assessing and evaluating three early regulatory approaches and understand the motivations behind these approaches, as well as the challenges anticipated, and the expectations held in these approaches. In general, this paper contributes to the knowledge of obstacles confronting innovative and potentially disruptive information technologies and novel services built upon these. In particular, this paper compares the motivations, challenges, and expectation of three small first-and-fast-mover jurisdictions. The forerunner efforts of these three jurisdictions may serve as role models and sounding boards for larger jurisdictions such as the EU and the US in their own regulatory aspirations on the subject matter. However, it appears as evident that harmonized regulation, at least to some degree, across major jurisdictions would help the token economy, as Liechtenstein phrased it, succeed more swiftly and more safely.

Future research will expand the comparative study by a number of other jurisdictions including Bermuda, France, Hong Kong, Singapore, and Switzerland among others. In a couple of years, it is planned to revisit the three early mover jurisdictions and assess the landscape of DLT/Blockchain/Token service providers and the effectiveness of the regulation comparing the perspectives of the various stakeholders on it.

\section{References}

[1] Anonymous, "Proposals for a DLT Regulatory Framework," ed. Gibraltar: HM Government of Gibraltar Ministry for Commerce Gibraltar Finance, 2017, pp. [1-20].

[2] Anonymous, "Advice: Initial Coin Offerings and Crypto-Assets," E. S. a. M. A. (ESMA), Ed., ed. Brussels, BE: European Union, 2019, pp. 1-49.

[3] Armstrong, P., "Regulation and DLT: Working to Strike the Right Balance," ESMA/2016/1613 ed. Paris: European Securities and Markets Authority (ESMA), 2016, pp. 1-5.

[4] Batog, C., "Blockchain: a proposal to reform high frequency trading regulation," Cardozo Arts \& Entertainment Law Journal, vol. 33, pp. 739-769, 2015.

[5] Blemus, S., "Law and blockchain: A legal perspective on current regulatory trends worldwide," Revue Trimestrielle de Droit Financier (Corporate Finance and Capital Markets Law Review) RTDF, pp. 1-15, 2017.

[6] Collingridge, D., The social control of technology. New York: St. Martin's Press, 1980.

[7] De Filippi, P. and S. Hassan, "Blockchain technology as a regulatory technology: From code is law to law is code," in arXiv preprint arXiv:1801.02507, ed, 2018, pp. 1-23.

[8] Dowlat, S., "Cryptoasset Market Coverage Initiation: Network Creation," ed. New York, NY: Satis Group, 2018, pp. 1-30.

[9] Eisenhardt, K. M., "Building theories from case study research," The Academy of Management Review, vol. 14, pp. 532-550, 1989.

[10] Fereday, J. and E. Muir-Cochrane, "Demonstrating Rigor Using Thematic Analysis: A Hybrid Approach of Inductive and Deductive Coding and Theme Development," International journal of qualitative methods, vol. 5, 2006.

[11] Flyvbjerg, B., "Five misunderstandings about casestudy research," Qualitative inquiry, vol. 12, pp. 219-245, 2006.

[12] Goitom, H., "Regulation of cryptocurrency in selected jurisdictions," The Law Library of Congress, Global Legal Research Center, Washington, DC, ReportJune 2018.

[13] Hasler, A., "Report and motion of the government to the Council of the Principality of Liechtenstein concerning the creation of a law on Tokens and TT service providers (Token and TT service provider 
law; TTTA) and the modification of other laws (Bericht und Antrag der Regierung an den Landtag des Fürstentums Liechtenstein betreffend die Schaffung eines Gesetzes über Token und VTDienstleister (Token- und VT-DienstleisterGesetz; TVTG) und die Abänderung weiterer Gesetze)," P. Minister, Ed., ed. Vaduz, Liechtenstein: Fürstentum Liechtenstein, 2019, pp. 1-384.

[14] Hileman, G. and M. Rauchs, "2017 Global Blockchain Benchmarking Study," ed, 2017, pp. 1119.

[15] Hughes, T., "Technological Momentum," in Does technology drive history? : the dilemma of technological determinism, ' M. R. Smith and L. Marx, Eds., ed Cambridge, Mass.: MIT Press, 1994, pp. 101-113.

[16] Kaal, W. A., "Initial Coin Offerings: The top 25 jurisdictions and their comparative regulatory responses," CodeX Stanford Journal of Blockchain Law \& Policy, pp. 1-27, 2018.

[17] Kakavand, H., N. Kost De Sevres, and B. Chilton, "The blockchain revolution: An analysis of regulation and technology related to distributed ledger technologies," Bart, The Blockchain Revolution: An Analysis of Regulation and Technology Related to Distributed Ledger Technologies (January 1, 2017), 2017.

[18] Kharif, O., "How's that ICO working out?," in Bloomberg Businessweek, ed. New York, NY: Bloomberg, 2018, pp. [1-5].

[19] Kiviat, T. I., "Beyond bitcoin: Issues in regulating blockchain transactions," Duke $L J$, vol. 65, pp. 569-608, 2015.

[20] Lastra, R. M. and J. G. Allen, "Virtual Currencies in the Eurosystem: Challenges Ahead," PE 619.020 ed. Brussels, Belgium: ECON Committee, European Parliament, 2018, pp. 1-56.

[21] Moses, L. B., "How to think about law, regulation and technology: Problems with 'technology'as a regulatory target," Law, Innovation and Technology, vol. 5, pp. 1-20, 2013.

[22] Ølnes, S., J. Ubacht, and M. Janssen, "Blockchain in government: Benefits and implications of distributed ledger technology for information sharing," Government Information Quarterly, vol. 34, pp. 355-364, 2017.

[23] Peters, G., E. Panayi, and A. Chapelle, "Trends in cryptocurrencies and blockchain technologies: a monetary theory and regulation perspective," ed, 2015, pp. 1-25.

[24] Ramsay, S., "The General Data Protection Regulation vs. The Blockchain: A legal study on the compatibility between blockchain technology and the GDPR," ed. Stockholm: Stockholm University, 2018, pp. 1-68.

[25] Rauchs, M., A. Glidden, B. Gordon, G. C. Pieters, M. Recanatini, F. Rostand, et al., "Distributed Ledger Technology Systems: A Conceptual Framework," ed. Cambridge, UK: Cambridge Centre for Alternative Finance, 2018, p. 109.

[26] Ritchie, J., J. Lewis, and E. Gillian, "Designing and selecting samples," in Qualitative research practice : a guide for social science students and researchers, J. Ritchie and J. Lewis, Eds., ed London ; Thousand Oaks, Calif.: Sage Publications, 2003, pp. 77-108.

[27] Scholl, H. J., "Involving salient stakeholders: Beyond the technocratic view on change," Action Research, vol. 2, pp. 281-308, 2004.

[28] Scholl, H. J. and M. P. R. Bolívar, "Regulation as Both Enabler of Technology Use and Global Competitive Tool: The Gibraltar Case," Government Information Quarterly, vol. 36, pp. [142], in print, 2019.

[29] Siegel, D., "The Token Handbook," in Hackernoon (blog). July vol. 27, ed, 2017.

[30] Strauss, A. L. and J. M. Corbin, Basics of qualitative research : techniques and procedures for developing grounded theory, 2nd ed. Thousand Oaks: Sage Publications, 1998.

[31] Swan, M., Blockchain: Blueprint for a new economy. Sebastopol, CA: O'Reilly Media, 2015.

[32] Urquhart, C., H. Lehmann, and M. D. Myers, "Putting the 'theory' back into grounded theory: guidelines for grounded theory studies in information systems," Information Systems, vol. 20, pp. 357-381, 2010.

[33] Vella, M., "Malta told to beef up police units with rise in gaming and crypto fraud: Rise of gaming, finance and crypto needs beefed-up economic crime police, Brussels tells Malta," in Malta Today, ed. Vjal ir-Rihan, San Gwann SGN 9016, Malta: MediaToday Co. Ltd,, 2019, pp. 1-2.

[34] Yeoh, P., "Regulatory issues in blockchain technology," Journal of Financial Regulation and Compliance, vol. 25, pp. 196-208, 2017.

[35] Yin, R. K., Case study research : design and methods, 4th ed. Los Angeles, Calif:: Sage Publications, 2009.

[36] Zetzsche, D. A., R. P. Buckley, and D. W. Arner, "The distributed liability of distributed ledgers: Legal risks of blockchain," University of New South Wales Law Research Series, vol. 52, pp. 1-43, 2018. 